\title{
Problems and Countermeasures of Multimedia Teaching in Higher Vocational Colleges
}

\section{Xiaopei Xu}

Changzhou ART Vocational College of Jiangsu, Changzhou, Jiangsu, 213000, China

\begin{abstract}
Among the Chinese national instruments, Pipa is the most expressive instrument. It has many skills in the process of playing pipa, and it is also difficult to get started. It makes many people who like Pipa to watch it far away.In the process of carrying out Pipa teaching work, there is a lack of unified teaching materials and the measurement standard of teaching results. The randomness of teaching work is very large, which leads to the current development of Pipa teaching has been affected to a certain extent. In this paper, based on the current multimedia teaching technology, the reform and innovation of Pipa teaching will be carried out, which will not only enhance the enthusiasm of students, but also improve the effect of classroom teaching.
\end{abstract}

\section{Keywords}

higher vocational colleges; multimedia teaching; Pipa teaching

\section{高职院校琵琶教学运用多媒体存在的问题与对策}

徐晓佩

常州艺术高等职业学校，中国・江苏常州 213000

摘 要

在中国民族乐器当中, 琵琶是最具表现力的一种弹拨乐器, 在琵琶演奏的过程中技巧比较多, 而且入门难度也比较高, 让许 多喜欢琵琶这件乐器的人敬而远之。在开展琵琶教学工作过程中, 缺乏统一的教材以及教学成果的衡量标准, 教学工作的随 意性非常大, 这导致当前琵琶教学的发展受到了一定程度的影响。在论文论述内容中, 将基于当前多媒体教学技术手段, 对 琵琶教学工作进行改革与创新，既增强学生学习的积极性，同时也提高课堂教学工作效果

关键词

高职院校; 多媒体教学; 琵琶教学

\section{1 引言}

多媒体教学已经成为当前高职院校开展教育教学工作的 一种重要辅助手段, 在很大程度上改变了过去传统教学课堂 的工作模式, 使教学过程中信息的传播质量以及传播数量都 得到了提升, 为了能够促使中国当前高职院校开展琵琶教学 工作的水平得到提高, 将多媒体教学手段融入到实际教学工 作当中, 是极为重要的。在论文论述内容中, 将对高职院校 的教学工作中运用多媒体教学手段以及方法的实际过程进行 论述。

【作者简介】徐晓佩（1989-），女，中国江苏常州人，本科 学历, 从事琵琶演奏教学研究。

\section{2 高职院校多媒体教学现状}

\section{1 教学盲目性较强}

对于多媒体教学手段来讲, 在实际应用的过程中, 许多 高职院校是应用多媒体课件为主要途径, 而且大多数都是进 行横向的举例论证和展示，并没有将多媒体教学手段以及设 备所拥有的逻辑推演以及交互功能发挥出来 ${ }^{[1]}$ 。对于多媒体 教学手段以及设备来讲, 虽然在一定程度上使教师教学时的 书写量变得更低，但并不意味着教师要完全依赖多媒体开展 教学工作。在这种情况下, 多媒体不仅不会提高教学工作质量, 还可能会导致教师将过多的精力放在多媒体使用上，而疏忽 使用多媒体的真正目的。 


\section{2 多媒体教学手段随意性较强}

在多媒体教学过程中, 主要的应用途径是通过课件来开 展相应的教学工作, 许多教师为了能够激发学生的学习兴趣, 并且吸引学生的注意力, 所以会选择将一些图表以及影像和 生效等效果在多媒体课件当中进行展示, 片面的追求了多媒 体所拥有的声像效果, 陷人了唯技术主义的误区 ${ }^{[2]}$ 。在这种 情况下的教学课堂当中, 所授主题内容及主要知识并没有得 到真正展现, 而是在过程中大量展现教师所制作好的课件和 剪辑的材料, 实则会对整个课堂教学工作产生严重干扰, 影 响学生的注意力, 使其没有真正集中在教学内容上。

\section{3 师生之间互动和交流频率降低}

教学工作的开展是比较复杂的过程, 在实际教学时教师 的任何言行举止都会对学生产生影响。但在当前的多媒体设 备应用过程中, 许多教师依靠多媒体开展教学工作, 只是单 纯的进行计算机的操作以及课件的演示和展示 ${ }^{[3]}$ 。当课堂上 的信息只被多媒体呈现给学生时, 教师在整个教学过程中, 既没有进行深入的知识内容讲解, 也没有进行板书的书写, 所以与学生之间的沟通和交流频率大大降低。

\section{3 至于多媒体的高职院校琵琶教学开展策略 \\ 3.1 琵琶教学中多媒体运用现状}

首先, 激发学生学习琵琶的兴趣。对于琵琶这一门乐器 来讲, 是中国民族乐器当中最具表现力的一种, 所以在演奏 的过程中指法丰富, 而且音色变化也较为明显, 但是正因为 如此琵琶的演奏技巧的特殊性, 入门学习具有一定的高难度, 所以导致许多有心学习琵琶这件乐器的人望而却步 ${ }^{[4]}$ 。为了 能够激发学生学习琵琶的兴趣以及增强积极性, 在教学过程 中针对多媒体教学课件进行了合理的应用以及适当的调整, 通过实践证明, 采用多媒体教学课件, 可以使批发教学工作 效果变得更好, 而且相比较传统的教学方法, 更能使课堂氛 围变得更加轻松, 活跃, 丰富。对于多媒体课件来讲, 丰富 多彩的视觉效果和存储的大量知识内容是最主要的特点, 在 开展琵琶教学的过程中, 将过去传统的纸质资料变成多媒体 课件进行展示, 尤其是在琵琶欣赏课当中, 可以使文学、艺术、 表演能够真正融为一体, 既让学生对琵琶艺术的相关内容进 行了解, 同时又能够通过影像以及视频资料等提高学生的人 文素质以及艺术修养。

其次, 则是教学过程更加生动而且直观。在实际教学过
程中, 有许多用语言和演示难以解决的问题, 可以通过多媒 体课件进行生动直观的演示。例如, 《十面埋伏》这首大型 的武曲套曲, 在演奏的过程中, 因为琵琶弹奏和演奏的方式 将诉说衷肠、栩栩如生的艺术表现力发挥出来, 整个乐曲展 现的是气势磅礴的战争场面。在整首乐曲当中, 既有景又有情, 情景之间相互交融, 将古时刀光剑影的战场刻画的栩栩如生。 在教学过程中, 为了能够使教学效果更好, 适当的运用多媒 体课件, 可以使十面埋伏的画面更好的展现在学生的眼前, 学生能够轻松而且准确的对音乐作品的背景以及内涵进行了 解, 然后在演奏的过程中更能够抒发出画面当中所体现出的 情感 ${ }^{[5]}$ 。

最后, 能够活跃课堂氛围。多媒体课件的运用, 可以实 现声情并茂的演示, 学生在学习过程中的视听神经会受到触 动, 使整个课堂教学氛围变得更活跃更积极。运用多媒体课件, 将声音、图像、动画以及影像等多个方面资源的优势真正发 挥出来, 结合琵琶演奏技法和艺术魅力, 在实际教学过程中 交相辉映, 真正营造出艺术学习的氛围, 在此过程中教师进 行从旁辅助的指导以及点拨, 能够使琵琶课程本身的艺术审 美特性得到最大程度的发挥。

\section{2 多媒体课件在琵琶教学运用过程中存在的问题}

在琵琶教学过程中, 多媒体本身属于一种辅助性的教学 工具, 虽然相比较于传统的教学方法, 多媒体课件拥有一定 的优势, 但是如果在教学过程中过于依赖多媒体课件, 那么 教师就会变成课堂上课件的放映员, 失去了传统教学过程中 教师在课堂上所拥有的地位。在传统教学课堂中, 虽然没有 多媒体课件作为辅助, 但是教师可以通过自身的语言以及手 势和神态与学生进行丰富的情感交流。但是在当前的教学过 程当中, 许多教师只是忙于操作计算机来播放课件, 而学生 只是通过银幕来获取知识, 所以师生之间的面对面演示和沟 通交流的严重缺失, 致使琵琶教学工作难以发挥真正的效果。

对于琵琶作品来讲, 自身的内涵比较丰富, 在理解以 及阐释的过程中, 从不同的角度以及不同的方面去进行解释 和理解, 都具有不同的意义。但是对于教学课件来讲, 本身 包含以及反映的内容是教师本人对作品的一种个性化理解, 并不是完全绝对正确的, 也并不是唯一的, 在实际教学过程 中, 优秀的课件可以使教学课堂的文化艺术氛围得到更好的 烘托, 这是传统教学课堂无法做到的。但在制作优秀课件的 过程中, 老师需要花费大量的时间和精力, 自身的教学任务 
繁重和工作压力比较大，教师并不是亲自制作，而是选择一 些专职人员代为制作，这不仅仅使得课件丧失了教学思想的 灵活映射, 而且也不能够真正阐释教师自身对作品的理解, 使得多媒体课件沦为一种形式上的教学手段, 丧失了多媒体 课件的优势 ${ }^{[6]}$ 。

\section{4 多媒体课件在琵琶教学中的应用建议 4.1 多媒体课件的科学应用}

对于教师来讲，在应用多媒体课件的过程中，需要对制 作和应用多媒体课件的相关技术进行全方位的掌握, 然后以 琵琶教学工作的特点和学生群体的特征, 对软件的类型进行 选择和设计。在课件设计的过程中, 最主要的就是要让教师 转变传统的教学观念, 既需要结合当前的教学工作目标, 同 时又需要结合多媒体的课件演示效果, 这样才能够使多媒体 课件真正发挥效果, 让学生既能够掌握应该掌握的重点以及 难点知识内容, 同时又能够对琵琶学习的记忆效果得到巩固。 在课件应用的过程中, 还需要考虑到动静结合以及音乐的搭 配等技术性问题, 还需要对课件和学生之间的交互效果进行 全面的研究分析, 能够通过多媒体课件展示和演示, 使整个 教学课堂真正有利于学生对知识内容进行准确的掌握, 并同 时锻炼自身的表达能力。

\section{2 课堂演示与讲授的全面结合}

对于多媒体课件的应用来讲, 最忌讳的就是教师全程进 行多媒体的演示, 而忽略与学生之间的沟通和交流, 在应用 多媒体课件的时候, 需要将传统的讲授教学模式和多媒体演 示进行有机结合。在传统教学过程中, 教师个性化的授课风 格能够在课堂上进行全方位的展示, 学生和教师之间会进行 微妙以及非常深入的心灵互动, 学生在教师的言行以及举止 和学术修养等影响下, 会产生潜移默化的影响。对于多媒体 课件的应用要以传统的课堂教学为基础, 在应用多媒体课件
的过程中, 应当做到有效以及针对性的应用, 使教学的正确 信息和质量得以保证，同时又能够通过多媒体课件，不断增 强学生对琵琶学习的兴趣以及积极性, 真正发挥多媒体课件 的优势, 但又不会喧宾夺主, 让学生的注意力被多媒体过于 分散。

\section{5 结语}

综上所述, 在当前的高职院校琵琶教学工作当中, 多媒 体设备以及教学理念的应用是新课程改革工作背景下, 对高 职院校琵琶教学工作提出的更高要求。但这并不意味着相关 教师需要完全依赖多媒体开展教学工作, 而是应当在传统教 学工作基础上对多媒体课件进行科学合理应用, 既能够发挥 传统课堂教学模式的优势, 同时又能够依托多媒体课件增加 知识信息传输量以及课堂氛围, 使琵琶教学工作能够变得更 加高质量而且高水平，让学生真正有所收获。

\section{参考文献}

[1] 刘秋玲. 高职院校琵琶教学运用多媒体存在的问题与对策 [J]. 中 国商界 ,2012(11):318.

[2] 屈宝丽. 多媒体在高职院校教学应用中存在的问题及解决对策 [J]. 软件导刊,2013,12(5):175-176.

[3] 周艳艳. 探究高职院校多媒体教学应用存在的问题及改进措施 [J]. 中国科技投资 ,2016(30):350.

[4] 陈鍗, 张晓雁. 高职院校多媒体教学存在的问题及对策 [J]. 教育探 索, 2011(5):53-54.

[5] 侯晓乐. 对高职院校琵琶教学中音乐审美能力培养的探索 [J]. 北 方音乐 , 2018,38(11):128-130.

[6] 余莉. 如何对高职院校零基础学生进行琵琶选修课教学 [J]. 宁夏 教育 ,2019(4):62-63. 